\title{
A Arqueologia Subaquática sob uma Perspectiva Teórica
}

\section{Marina Fontolan ${ }^{1}$}

Resumo: A Arqueologia Subaquática é uma prática arqueológica. Ela teve seu início como disciplina científica no ano de 1960, numa escavação realizada em Cape Gelidonya, na Turquia, sob a coordenação do arqueólogo americano George Fletcher Bass. Pensar quais os contextos que estão envolvidos neste início é o objetivo deste artigo, que também procura a pensar a questão da relação entre Arqueologia e História. Para tal, então, foi escolhido fazer uma análise em três frentes de modo a deixar à mostra a idéia da importância de se considerar o contexto histórico, sobretudo para justificar as mudanças e as escolhas realizadas na época.

Palavras-Chave: História, Arqueologia, Guerra Fria, Arqueologia Subaquática, História da Arqueologia, George Fletcher Bass.

\section{Introdução}

Este artigo visa a dois objetivos. O primeiro deles é pensar, a partir da perspectiva de Michael Shanks (1996), que considera fundamental pensar os diversos contextos que podem ser utilizado para interpretar o desenvolvimento da prática arqueológica. Assim sendo, o início da prática de uma Arqueologia Subaquática tida por

\footnotetext{
${ }^{1}$ Graduanda em História pela Universidade Estadual de Campinas (UNICAMP), bolsista de Iniciação Científica com apoio financeiro da Fundação de Amparo à Pesquisa do Estado de São Paulo (FAPESP).
} 
científica, na década de 1960, será estudado sob este olhar. O segundo, e não menos importante, é pensar a relação entre Arqueologia e História.

Desta forma, foram feitas algumas escolhas que aqui devem ser enunciadas e justificadas. Primeiro, a escolha do tema deste artigo está condicionado a um projeto de pesquisa em curso, na qual se tem o objetivo de contextualizar historicamente as obras do arqueólogo George Fletcher Bass, que é arqueólogo americano tido como pioneiro na área por ter sido o diretor da primeira escavação tida como científica em um sítio submerso, num estudo de caso sobre a História da Arqueologia. Em segundo lugar, a análise deste início será realizada a partir do relatório parcial desta primeira escavação científica, focando a importância de se pensar a História da Arqueologia, sob a ótica do contexto histórico, e a relação entre ambas as disciplinas que envolvem esta análise, História e Arqueologia.

Assim sendo, o artigo divide-se numa perspectiva teórica, que tem por objetivo mostrar a importância de se pensar o(s) contexto(s), sobretudo quando se trata de história das ciências. Depois, o estudo será dedicado a uma análise acerca do início da prática da Arqueologia Subaquática, considerando diversos contextos. Por fim, já no capítulo conclusivo, será feita uma análise 
mais sistemática acerca da relação entre Arqueologia e História e sua importância para o estudo de caso proposto.

\section{Considerações Teóricas}

É necessário, desta forma, fazer algumas considerações acerca dos pressupostos teóricos, uma vez que toda leitura é condicionada e, por isso, partimos da perspectiva teórica aqui adotada. Primeiro cabe ressaltar que este estudo se insere sob uma perspectiva que é, ao mesmo tempo, pós-processualista e pósmoderna. Pós-processualista num âmbito arqueológico, no qual se privilegia as continuidades e descontinuidades das fontes a serem analisadas, bem como considerar que a Arqueologia é uma ciência social e ela está inserida e ligada à sociedade de uma maneira geral (JOHNSON, 2008:167-168). Pós-modernista num âmbito da disciplina histórica, na qual privilegia não apenas aquilo que é considerado central, mas sim se considera o periférico, sobretudo quando se trata de recortes geográficos; tem-se a noção de que nada é sólido ou fixo, mas sim que depende de diversos interesses, que não são, de forma alguma, universais (JENKINS, 2005: 94); e, por fim, considerar que "vivemos num mundo pós-moderno e que essa condição afeta o que eu ou você podemos conversar sobre a história" (JENKINS, 2005:93). 
Cabe, ainda, fazer uma última consideração. É fundamental considerar $\mathrm{o}(\mathrm{s})$ contexto(s) histórico(s) para pensar as mudanças que envolvem a prática da Arqueologia Subaquática, historicizando-a. Isto porque se considera, como Margarita Díaz-Andreu, que a Arqueologia é "um produto histórico e cultural, um conjunto de práticas criado socialmente, que não deve ser isolado de seu quadro histórico e sócio-cultural na qual foi formado" (DíAZ-ANDREU, 2007:4). ${ }^{2}$ Assim sendo, ao analisar os discursos dos arqueólogos, nota-se que, em suas propostas de análise da cultura material e da história da Arqueologia, há a menção da importância de se pensar o contexto de produção daquilo que está sendo analisado pelo autor.

Assim, considerando as idéias de Michael Shanks (1996), Richard Hingley (2009) e Kristian Kristiansen (2009), nota-se que a idéia da importância de se pensar o(s) contexto(s) é algo comum nestes três autores. No entanto, estes contextos aparecem de maneira diferente, já que eles lidam com diferentes temas e, por isso, será feita aqui uma breve explanação de suas idéias.

Em sua obra Classical Archaeology of Greece: Experiences of the Discipline, publicada em 1996, Michael Shanks tem o objetivo de pensar porque arqueologia Clássica, sobretudo aquela que lida com questões ligadas à Grécia Antiga, assim se apresenta na

\footnotetext{
${ }^{2}$ Tradução minha.
} 
atualidade. O capítulo "Rudiments of Social Archaeology" mostra a importância de se pensar os diversos contextos envolvidos para um dado objeto, criando assim, uma linha de pensamento que ele chama de Arqueologia Social (SHANKS, 1996:152). O título de seu capítulo justifica-se pela idéia do autor em trabalhar com arqueólogos processualistas (SHANKS, 1996: 131-143), que representam um primeiro esforço de pensar aspectos sociais através da arqueologia, sobretudo sob a ótica de mudanças de conceitos e poder (SHANKS, 1996: 152). Sua crítica a esse tipo de análise, justamente refere-se à idéia de que eles não se utilizam de contextos para o estudo da antigüidade, que leva muito em conta uma tipologia seriada e em análises estatísticas. Portanto, a idéia de se considerar um contexto histórico como uma forma de pensar as mudanças ocorridas no desenvolvimento de uma ciência, por exemplo, ou, ainda, pensar nas mudanças presentes em representações do papel feminino em vasos áticos.

Richard Hingley, em seu capítulo "Cultural Diversity and Unity: Empire and Rome", publicado na obra Material Culture and Social Identities in the Ancient World, escreve acerca das mudanças nos discursos sobre Roma Antiga e sua relação com um contexto histórico, sobretudo contemporâneo (HINGLEY, 2009:54). Aqui, o autor irá considerar que "este novo entendimento é relacionado a 
como as interpretações do passado clássico desenvolveram-se num contexto sobre nossas idéias acerca do mundo contemporâneo" (HINGley, 2009:60). ${ }^{3}$ Ou seja, pensar o contexto histórico é importante para compreender a maneira como o passado foi pensado, pois este molda a maneira de olhar o passado.

Kristian Kristiansen (2009), em seu capítulo "The Discipline of Archaeology", publicado na obra The Oxford Handbook for Archaeology, o autor fará algumas considerações acerca da disciplina, sobretudo no que concerne às suas teorias e contextos de mudanças na maneira de pensar a Arqueologia, tentando, desta maneira, definir a disciplina. Já no final deste capítulo, Kristiansen afirmará que

\footnotetext{
“(..) a história da arqueologia é uma importante área de estudo, não menos importante é sua relação com os diferentes grupos de interesse que têm empregado a Arqueologia em seus ideais políticos" (KRISTIANSEN, 2009:31).
}

Ou seja, a História da Arqueologia é uma área importante para a disciplina como um todo. No entanto, há a necessidade de pensar esta história pelo viés de seu contexto.

\footnotetext{
${ }^{3}$ Tradução minha.

${ }^{4}$ Tradução minha.
} 
Thomas C. Patterson, em sua obra A Social History of Anthropology in the United States, publicada em 2001, mostrará a importância de se pensar o contexto histórico para notar e justificar as mudanças ocorridas na Antropologia: “(...) o estudo da Antropologia é um processo dialético. É moldado pelo que o mundo é e quem são os antropólogos e as diversas pessoas que o estudam (...)" (PATTERSON, 2001:2). ${ }^{5}$ Vale notar que, sendo americano, Patterson pode ser considerado um arqueólogo, já que a disciplina nos Estados Unidos desenvolveu-se baseada nesta ciência (FUNARI, 2006: 23).

Portanto, de uma maneira geral, os autores aqui estudados demonstram a importância de se pensar o contexto, sobretudo histórico. Cabe dizer, ainda, que todos estes se inserem numa perspectiva pós-processualista e que todos, nas obras analisadas, lidam com o desenvolvimento e as mudanças na forma de se pensar a Arqueologia, mesmo que sob óticas diferentes.

\section{Os Vários Contextos do Início da Arqueologia Subaquática} Científica

Estudar o início da prática da Arqueologia Subaquática científica significa considerar diversos contextos. No entanto, não há

\footnotetext{
${ }^{5}$ Tradução minha.
}

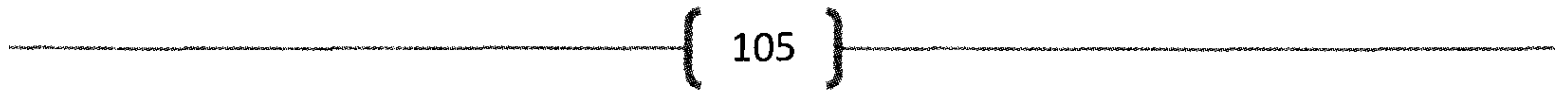


possibilidades de abarcar todos eles e, por isso, foram feitas algumas escolhas que já serão aqui postas e justificadas.

A primeira delas é o contexto histórico que será levado em consideração para a análise. No entanto, há diversas possibilidades aqui, que vão de uma história mais política a uma mais cultural, que, embora diferentes, nunca serão isoladas. Neste âmbito, o início da prática da Arqueologia Subaquática será lido sob um viés político, que foi muito peculiar na época em questão. Este contexto refere-se, justamente, a um início do acirramento do período que ficou conhecido por Guerra Fria.

A segunda escolha feita é em relação ao contexto tecnológico. A prática da Arqueologia Subaquática, mais do que a Arqueologia praticada em meio terrestre, depende de tecnologias específicas para que os pesquisadores cheguem ao campo e consigam realizar suas tarefas. Claro que a Arqueologia de uma maneira geral depende de diversas tecnologias para que sua prática se torne a mais precisa possível. No entanto, devido às particularidades de se realizar uma escavação em um meio submerso (cf. RAMBELLI, 2002; BASS, 1971), como remoção de sedimentos sem prejudicar muito a visibilidade do mergulhador, fotografias e, também, a própria idéia de poder respirar debaixo da água. Portanto, torna-se fundamental 
pensar o desenvolvimento de tecnologias para que a prática da Arqueologia Subaquática fosse possibilitada.

A terceira e última delas é sobre a relação arqueólogo/sítio. Como será mostrado, as primeiras tentativas de explorar os sítios submersos foram realizadas com os arqueólogos na costa, coordenando o trabalho de mergulhadores profissionais. A prática de uma Arqueologia Subaquática científica, portanto, está relacionado ao arqueólogo se tornar mergulhador, ir a sítio e fazer seu trabalho de escavação com a mesma precisão que se realiza num meio terrestre.

Além destes contextos mais gerais, cabe fazer outra consideração. Estes contextos não se esgotam, mas possuem outros aspectos. Assim, considerar as personagens que se envolveram no desenvolvimento na prática científica da Arqueologia Subaquática e, como já dito, alguns casos de escavação que antecederam o realizado por George Fletcher Bass na Turquia tornam-se fundamentais e serão considerados nesta análise.

\section{O Contexto Político}

Com o fim da Segunda Guerra Mundial, várias crises políticas ocorreram pelo mundo. Isto colaborou para a demarcação das zonas de influência, que perduraram por todo o período da Guerra Fria. Uma destas crises envolveu, justamente, a Turquia.

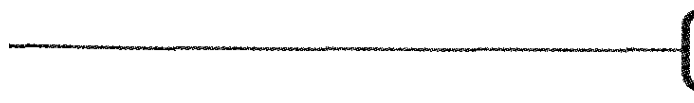


Após as Conferências de Yalta e Potsdam, realizadas em fevereiro e Julho de 1945, que, respectivamente, definiram as fronteiras no pósguerra e, também, ajudaram no estabelecimento das zonas de influência, a Turquia ficou sendo considerada zona neutra, ou seja, ela não pertenceria a nenhuma das esferas que haviam sido estabelecidas.

É importante destacar que a Turquia está numa posição considerada estratégica: mesmo sendo considerada uma zona neutra em relação às influências soviéticas ou americanas, ela se encontra entre a União Soviética e a Federação Balcânica, que ficou sob influência soviética. Cabe notar, também, que a Turquia possui grande parte de sua costa voltada para o Mar Negro. O controle desta região significaria, assim, um controle total do Mar Negro, com saída facilitada para o Mediterrâneo e, conseqüentemente, para o Oriente Médio e a Europa Ocidental, algo que preocupava a influência que os americanos haviam conquistado na região.

A crise da Turquia começou em agosto de 1947, quando os soviéticos pediram aos turcos uma revisão da Convenção de Montreux (Offner, 2002: 167). Este concedeu aos turcos o controle dos estreitos de Dardanelos e do Bósforo. Ambas correntes historiográficas acerca do período, tanto aquela que culpa os soviéticos pela Guerra Fria, quanto aquela que responsabiliza os 
Estados Unidos por 'ataques' à União Soviética, cujas ações são tidas por defensivas (PATERSON, 1986), colocará esta crise como iniciada pelos soviéticos, embora a questão da reação americana seja considerada de maneiras diferentes.

Para o diplomata e professor de história ${ }^{6}$ Melvyn P. Leffler, o objetivo dos soviéticos era de “(...) unir-se aos poderes do Mar Negro, formular um novo set de regras e estabelecer uma junta de defesa nos estreitos. A nota diplomática soviética (...) provocou diversas ações nos mais altos níveis da administração do governo Truman" (LEFFLER, 1992:123). ${ }^{7}$ Ou seja, o provável aumento da influência soviética no Mar Negro e, sobretudo, em seus estreitos é colocado como a causa principal da tensão.

A reação americana ante este problema diplomático foi "comunicar suas dúvidas aos russos, pedir aos turcos que resistissem e insistir que um novo regime para os estreitos não deveria ser formado apenas pelos poderes do Mar Negro" (LEFFLER, 1992:124). ${ }^{8}$ Ou seja, ao notar a pressão soviética para a obtenção de maior influência na região, os Estados Unidos interferem e passam a exercer grande influência no país, criando, inclusive, bases militares, que seriam usadas pelos americanos para lançar bombas em áreas

\footnotetext{
${ }^{6}$ Fonte: http://www.virginia.edu/history/user/34, acessado em 12/6/2010.

${ }^{7}$ Tradução minha.

${ }^{8}$ Tradução minha.
} 
petrolíferas soviéticas, em casos de um confronto armado, bem como proteger pontos estratégicos, tais quais Canal de Suez (LEFFLER, 1992:125) e o Mar Negro.

Mas, por que esta estratégia defensiva? O que mudou no pensamento americano em relação à Turquia desde as conferências de Yalta e Potsdam? O medo da revisão turco-soviética das regras da Convenção de Montreux (Offner, 2002: 167) e da criação de uma Junta de Defesa (LeFfler, 1992: 123), faria com que o poder soviético ganhasse grande influência no Mar Negro e seus estreitos. Desta forma, sob uma ótica americana, a conquista da Turquia e da Grécia seria facilitada e faria com que o avanço da União Soviética pelo Mediterrâneo e $\mathrm{o}$ Oriente Médio fosse possibilitado estrategicamente, podendo significar perda das zonas de influência pelos Estados Unidos, sobretudo aquelas adquiridas durante as conferências do pós-guerra.

Cabe, por fim, fazer um último esclarecimento: o estudo da crise da Turquia em 1947, como será apresentado, foi escolhido, justamente, pelo início da prática da Arqueologia Subaquática ter sido ali, no ano de 1960. Ao pensar o início da Arqueologia Subaquática, deve-se levar em consideração todo o contexto político analisado. No entanto, esta prática não deve seu desenvolvimento apenas a seu contexto político, mas também, deve-se pensar a 
influência trazida pela criação de novas tecnologias. Assim, passarei a fazer uma breve análise da influência da tecnologia para o início da Arqueologia Subaquática e de Bass, para, então, analisar o início da Arqueologia Subaquática científica como um todo.

\section{O Contexto Tecnológico}

Dentre as diversas tecnologias utilizadas para pesquisas e escavações em ambiente subaquático, aquela que se tornou mais proeminente para o início das escavações foi o desenvolvimento do Aqualung em 1947 (Rambelli, 2002:27). Essa tecnologia se constitui em dois cilindros metálicos carregados com ar comprimido, uma borracha que regula a pressão do ar e uma mangueira que conduz o ar até a boca. Esta aparelhagem simples resultou numa popularização do mergulho, tornando-o um esporte, que poderia ser praticado por qualquer pessoa que aprendesse a lidar com a tecnologia.

Foi a partir da criação e popularização do Aqualung que diversos arqueólogos puderam pensar num melhor acesso aos sítios submersos, fazendo surgir a idéia da possibilidade de se realizar escavações arqueológicas em meios subaquáticos. Aliás, vale afirmar que 
Cadernos de Clio, Curitiba, n..$^{\circ}$ 2, 2011

"da mesma forma que a trajetória História da Arqueologia Terrestre foi iniciada por aventureiros e colecionistas, os mergulhadores aventureiros e sua relação com os artefatos submersos fazem parte da História da Arqueologia Subaquática e contribuíram diretamente para o desenvolvimento de equipamentos e de técnicas que levaram ao atual estado do mergulho arqueológico científico" (RAMBELLI, 2002:17).

Em outras palavras: as tecnologias e técnicas para o mergulho e a exploração em ambientes subaquáticos nem sempre foram criadas pelos próprios arqueólogos e, nem sempre, para o propósito da prática da Arqueologia. Aliás, a idéia da prática arqueológica em meio subaquático ter sido, da mesma forma da arqueologia terrestre, iniciada por amadores e aventureiros, perdurará até a primeira escavação tida por científica, realizada em 1960, sob a direção de George Fletcher Bass na Turquia. Assim, pensar as tentativas que precedem a esta escavação também faz parte do contexto de desenvolvimento da disciplina.

\section{As Tentativas Predecedentes}

Podem-se citar vários exemplos destas tentativas, mas dois mostram-se importantes: a primeira delas é o caso das escavações no Lago Nemi e o segundo, o caso da escavação da embarcação, cujo sítio ficou conhecido como Grand Congloué. 
O caso do Lago Nemi é tido como um caso especial para a história da Arqueologia Subaquática, pois após séculos de tentativas de escavação, normalmente infrutíferas, o lago acabou sendo drenado na época do regime fascista. Este ato faz surgir duas embarcações romanas e estréiam uma nova modalidade de estudo em Arqueologia, que é a construção naval (MUCKELROY, 1978: 13). É importante notar que os arqueólogos e antiquaristas envolvidos nas mais diversas tentativas de escavação não sabiam mergulhar e valeram-se do uso de outras técnicas para chegar ao sítio: contrataram mergulhadores profissionais, utilizou-se de equipamentos e redes para puxar o que podiam, até o ponto que houve a decisão de drenar o lago.

O outro caso importante já citado é a exploração de outra embarcação romana, na costa da França, cujo local ficou conhecido como Grand Congloué e foi realizada durante a década de 1950. Esta exploração, tal qual ocorreu com o caso do lago Nemi, não tinha um arqueólogo que soubesse mergulhar, ou seja, que fosse a campo. O máximo que se conseguiu foi que um arqueólogo coordenasse os trabalhos através de um sistema de vídeo.

Em ambos os casos, nota-se que a escavação do sítio, quando sequer tinha um arqueólogo envolvido, não possuía um especialista que mergulhasse. Desta forma, a exploração destes sítios 
teve de ser adaptada, ou através da drenagem ou através de um sistema de vídeo, de forma que um arqueólogo pudesse coordenar minimamente os trabalhos. Assim sendo, pensar a idéia da importância do arqueólogo mergulhar e ir a campo é de grande importância ao considerar-se a história do desenvolvimento da disciplina.

\section{Relação Sítio/ Arqueólogo}

George Fletcher Bass é um arqueólogo histórico, nascido nos Estados Unidos, cuja especialização é em Arqueologia clássica. Seu trabalho pode ser considerado como pioneiro, justamente, pelo fato de ele ter aprendido a mergulhar, ir a campo e escavar. Além deste aspecto, seu pioneirismo também se deveu à idéia do arqueólogo em adaptar as técnicas utilizadas em escavações terrestres para os sítios submersos, fazendo com que os relatórios de escavação ficassem muito próximos daqueles de sítios terrestres, também é considerado como parte de seu pioneirismo.

É à habilidade de mergulhar que o arqueólogo subaquático Gilson Rambelli vai dar os créditos à 'cientifização' da Arqueologia Subaquática. Afinal, na ótica do autor

"(...) foi o fato de os arqueólogos mergulharem que proporcionou finalmente o estabelecimento de uma 
Cadernos de Clio, Curitiba, n. $^{\circ}$ 2, 2011

distinção nítida entre a atividade aventureira e a pesquisa científica, pois permitiu o desenvolvimento e/ou adaptação de inúmeros métodos e técnicas, garantindo às pesquisas subaquáticas o mesmo vigor científico das pesquisas arqueológicas terrestres" (RAMBELLI, 2002:30).

Adquirida esta nova habilidade, Bass se tornou responsável pela escavação no sítio de Cape Gelidonya, na costa da Turquia. É interessante notar que, mesmo com a criação de uma tecnologia relativamente fácil de ser usada a idéia de o arqueólogo ir a campo é muito recente e veio, justamente, com Bass. Atualmente, saber mergulhar é tido como uma habilidade necessária para se tornar um arqueólogo subaquático.

No entanto, como já mencionado, Bass não se tornou pioneiro apenas por sua habilidade de mergulhar. Assim sendo, na ótica dos arqueólogos marítimos Joe Flatman e de Mark Staniforth, foi em

"Cape Gelydonia (Turquia) a escavação de um naufrágio datado do século XII a.C. em 1960, foi a primeira escavação subaquática totalmente relatada e que ajustou altos padrões através do uso de novos métodos projetados para maximizar a coleta de informações, muitos usados até hoje. Então Bass refinou estas técnicas em uma série de impressionantes escavações em naufrágios antigos no leste do 
Cadernos de Clio, Curitiba, n. ${ }^{\circ}$ 2, 2011

Mediterrâneo durante as décadas de 1960 e 1970" (FLATMAN e STANIFORTH, 2008: 169). ${ }^{9}$

O pioneirismo de Bass está também relacionado à adaptação de técnicas da Arqueologia terrestre para a escavação de sítios submersos.

É claro que não foi apenas Bass que realizou esta primeira escavação em Cape Gelidonya, mas sim havia outros personagens envolvidos no processo. Desta forma, considerar sua influência para o desenvolvimento da Arqueologia Subaquática torna-se fundamental. Aqui, será dado destaque ao papel de Peter Throckmorton nesta primeira escavação. Ele foi um jornalista americano que estava procurando sítios submersos na costa da Turquia (BASS, 1961:267).

Como justificar a atitude de Throckmorton? A Turquia havia passado por uma crise política e havia, então, passado a pertencer à zona de influência americana. O uso de um novo campo de uma ciência já consolidada seria, também, uma maneira de consolidar a influência na região. Ou seja, a o poder americano sobre outros países na época também se deu por vias culturais, na qual o influenciado recebe os "avanços" do influenciador, embora este

\footnotetext{
${ }^{9}$ Tradução minha.
} 
"recebimento" seja adaptado à realidade do país que recebe (LAFUENTE, 2000:156).

\section{Conclusão}

Assim, são estes os contextos que se pode entender o início da prática da Arqueologia Subaquática. Além disso, vale dizer que a mudança de pensamento em relação ao uso da tecnologia de mergulho pelos próprios arqueólogos, trazendo-lhes a oportunidade de trabalhar em campo mostra-se extremamente importante para o desenvolvimento da disciplina. A atitude de Bass em aceitar se tornar mergulhador e levar as técnicas e práticas de escavações terrestres para um sítio submerso caracteriza sua atuação pioneira. São estes os três grandes elementos que devem ser considerados para pensar o início deste novo campo da Arqueologia.

A teoria proposta aqui consegue encaixar-se perfeitamente ao estudo de caso proposto. Shanks (1996), ao falar sobre os contextos que devem ser levados em conta, acaba sendo contemplado. Ele afirma que os processualistas não abarcam todos os contextos possíveis (SHANKS, 1996: 131-143), porém abarcar todos os contextos acaba sendo uma tarefa impossível, já que cada contexto tem seu próprio contexto e assim por diante, fazendo com que o pesquisador corra o risco de perder o foco de sua pesquisa. Ou seja, 
há a necessidade de se fazerem escolhas e estas devem ser salientadas e justificadas.

Quando se consideram as idéias de Richard Hingley (2009), coloca-se o estudo feito em cheque com o presente: ele está sendo escrito num contexto histórico que tem sido definido como globalização. Estes contextos devem ser levados em consideração, pois eles irão direcionar nosso olhar sobre o passado.

Por fim, ao considerar as idéias de Kristiansen (2009), temos assim, um bom encaixe entre a teoria e o estudo de caso apresentado. Da mesma maneira do autor, creio que é fundamental pensar a história do desenvolvimento da disciplina, sobretudo para mostrar a idéia de que o conhecimento não é algo neutro e, sim, guiado por interesses e pelo contexto vivido. Assim, pensar o discurso da prática arqueológica em seus contextos e interesses torna-se fundamental.

No entanto, deve-se considerar a relação Arqueologia e História e a importância de se pensar esse assunto para o caso do desenvolvimento da Arqueologia Subaquática tida por científica. Ao pensar a história de uma ciência, tanto as noções históricas quanto as da ciência estudada acabam entrando em contato.

Assim, sendo, ao pensar-se a História da Arqueologia, ambas as disciplinas entram em contato e relacionam-se. Suas 
teorias, tal qual fora sugerido, tornam-se complementares, uma vez que pensar o contexto histórico e a maneira como ele direciona o olhar são teorias que pertencem a ambas as disciplinas. Aliás, ao pensar-se a História da Arqueologia das fontes escritas, deve-se, à maneira dos pós-modernistas, pensar suas continuidades e descontinuidades que estas apresentam e fazer delas seu principal foco de análise. Aos pós-processualistas, fazer uma leitura do contexto histórico no qual tal discurso arqueológico foi desenvolvido é uma grande contribuição para ambas as ciências, mesmo que esta seja condicionada ao que vivemos no presente, como propõem tanto os pós-modernos, quanto os pós-processualistas.

Desta forma, ambas as disciplinas têm o que oferecer para pensar a história da Arqueologia, sem a necessidade de sobrepor uma à outra, tal qual ocorre em alguns casos da Arqueologia Histórica em que as fontes escritas são tidas como verdadeiras e cuja cultura material é renegada a provar ou não tal texto, tal qual afirmam autores como Antony Snodgrass (1987:39) e Ian Morris (2000:3). Ou seja, neste âmbito a Arqueologia torna-se uma disciplina auxiliar da história, o que não é algo defensável pela autora, que acredita que ambas são disciplinas independentes e de igual importância para o estudo do passado. 
Ao considerar o caso da Arqueologia Subaquática, estas proposições devem ser levadas em conta. $O$ contato entre as disciplinas, aqui ocorre de igual maneira, sobretudo por que, como afirma Bass, a Arqueologia Subaquática é Arqueologia, ela é um ramo desta ciência consolidada (BASS, 1971:17).

Para finalizar, os autores teóricos aqui utilizados para explicitar a importância de se pensar contexto(s) nem sempre se reportam à relação entre história e a ciência do qual se fazem um estudo de caso. No entanto, a idéia de contexto implica, assim, em pensar um contexto histórico, que deve ser escolhido e justificado: econômico, político, cultural e tecnológico, por exemplo. Portanto, pensar o contexto significa abrir um diálogo para ambas as disciplinas, uma vez que se utiliza da história para pensar as mudanças nos discursos sobre a Arqueologia, sem a necessidade de sobreposição de uma na outra.

\section{Agradecimentos}

Agradeço, primeiramente, a meus orientadores, Pedro Paulo Abreu Funari e Gilson Rambelli. Agradeço, também, à Fundação de Amparo à Pesquisa do Estado de São Paulo, pela concessão e, também, renovação da bolsa de Iniciação Científica e ao apoio institucional do Departamento de História do Instituto de Filosofia e 
Ciências Humanas da Universidade Estadual de Campinas (DH/IFCH/UNICAMP) e do Núcleo de Estudos e Pesquisas Ambientais. Por fim, agradeço aos Aline Carvalho, André Leonardo Chevitarese e José Geraldo da Costa Grillo pela oportunidade de uma graduanda participar do curso de pós-graduação intitulado "Discussões Recentes da Arqueologia Histórica e Estudos de Caso: Grécia, Roma e Modernidade", ministrado no $1^{\circ}$ Semestre de 2010.

\section{Referências}

BASS, George Fletcher. "The Cape Gelidonya Wreck: Preliminary Report”. American Journal of Archaeology, Vol. 65, No. 3, Jul., 1961, pp. 267-276. http://www.jstor.org/stable/501687, acessado em 07/01/2009.

- Arqueologia Subaquática. Lisboa: Editorial Verbo, 1971, $13^{\circ}$ volume da coleção História Mundi.

Díaz-Andreu, Margarita. A World History of Nineteenth-Century Archaeology: Nationalism, Colonialism, and the Past. Oxford: Oxford University Press, 2007.

Flatman, Joe; Staniforth, Mark. "Historical Maritime Archaeology". In BEAudry, Mary C.; Hicks, Dans (ed). The Cambridge Companion to Historical Archaeology . New York; Cambridge University Press, 2008. 
FunARI, Pedro Paulo Abreu. Arqueologia. São Paulo: Contexto, 2006.

HINGLEY, Richard. "Cultural Diversity and Unity: Empire and Rome”. In: Hales, Shelley; Hodos, Tamar (ed). Material Culture and Social Identities in the Ancient Word. Cambridge: Cambridge University Press, 2009.

Jenkins, Keith. A História Repensada. São Paulo: Contexto, 2005. JoHnson, Matthew. Archaeological Theory: an Introduction. Oxford: Blackwell, 2008.

Kristiansen, Kristian. "The Discipline of Archaeology". In: Cunliffe, Barry; Gosden, Chris; Joyce, Rosemary A. (ed). The Oxford Handbook for Archaeology. New York: Oxford University Press, 2009.

LAFUENTE, Antonio. "Enlightenment in an Imperial Context: Local Science in the Late-Eighteenth-Century Hispanic World". Osiris, 2nd Series, Vol. 15, Nature and Empire: Science and the Colonial Enterprise, (2000), pp. 155-173. http://www.jstor.org/stable/301946, acessado em 02/07/2008.

Leffler, Melvyn P. A Preponderance of Power: National Security, the Truman Administration and the Cold War. Stanford: Stanford University Press, 1992.

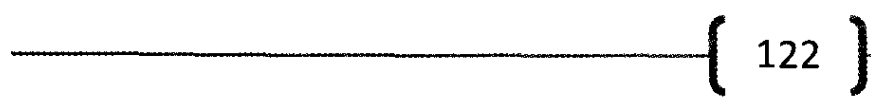


Morris, Ian. "Archacology as Cultural History". In Archeology as Cultural History. Oxford: Blackwell Publishers, 2000. Pp.3-33. MuCKelroy, Keith. Maritime Archaeology. Cambridge University Press: London, 1978.

OfFner, Arnold A. Another Such Victory: President Truman and the Cold War 1945-1953. Stanford: Stanford University Press, 2002 .

Paterson, Thomas G. "The Origins of the Cold War". Magazine of History, Vol. 2, No. 1 (Summer, 1986), pp. 5-9, 18. http:// www.jstor.org / stable/ 25162491, acessado em 04/11/2009.

Patterson, Thomas C. A Social History of Anthropology in the United States. New York: Oxford International Publishers, 2001. Rambelli, Gilson. Arqueologia Até Debaixo D’água. São Paulo; Maranta, 2002.

SHANKS, Michael. Classical Archaeology of Greece: Experiences of the discipline. Londres: Routledge, 1996.

SNODGRASS, Antony. "Archaeology and History". In An Archaeology of Greece: The Present State and Future Scope of a Discipline. Los Angeles: University of California Press, 1987. Pp. 36-66. 